\title{
The Coordination Compound of Ga(III) with Stillbazo in the Presence of Cetyl Pyridinium Chloride as a Surface Active Compound
}

\author{
Shahin M. Bayramov, Aydin M. Pashajanov, Gulu G. Abbasova, Melahat I. Ganbarova, \\ Sona M. Gasanova \\ Institute of Catalysis and Inorganic Chemistry Named after M. Nagiyev, National Azerbaijanian Academy of Sciences, \\ Baku, Azerbaijan \\ Email: veliyeva_g@mail.ru, veliyeva_g23@yahoo.com
}

How to cite this paper: Bayramov, Sh.M., Pashajanov, A.M., Abbasova, G.G., Ganbarova, M.I. and Gasanova, S.M. (2019) The Coordination Compound of $\mathrm{Ga}$ (III) with Stillbazo in the Presence of Cetyl Pyridinium Chloride as a Surface Active Compound. Journal of Materials Science and Chemical Engineering, 7, 58-63.

https://doi.org/10.4236/msce.2019.710006

Received: September 3, 2019

Accepted: October 27, 2019

Published: October 30, 2019

Copyright $\odot 2019$ by author(s) and Scientific Research Publishing Inc. This work is licensed under the Creative Commons Attribution International License (CC BY 4.0).

http://creativecommons.org/licenses/by/4.0/

\begin{abstract}
The coordination compound of gallium (III) with stillbazo-stillbene-4,4'-bis [(1-azo)3,4-dihydroxybenzene]-2,2'-disulfonic acid has been investigated by spectrophotometric method in the presence of cetyl pyridinium chloride (CPC) as surface active compound. It has been determined that the mixed ligand complexes were formed with the ratio of 1:2:4 in CPC-mediated phase. The molar coefficient and the stability constant of the complex compound $\beta_{k}$ $=6.8 \times 10^{9}, \varepsilon_{\kappa}=66,834$ have been studied by various spectrophotometric methods. The effect of $\mathrm{pH}$, time, temperature, concentration of the reagents and $\mathrm{CPC}$ on formation of the unmixed and mixed ligand coordination compounds has been also studied. It has been determined that the Beer's law is respected within $0.008-10 \mu \mathrm{g}$ of $\mathrm{Ga}$ (III) in $25 \mathrm{~mL}$ solution. The technique of the photometric determination of gallium in natural compositive objects and industrial objects has been developed.
\end{abstract}

\section{Keywords}

Gallium, Stillbazo, Surface-Active Compound, Concentration of the Reagents, Spectrophotometric Method

\section{Introduction}

The azoderivatives of pyrocatechin as analytical reagent have been studing in different research works [1] [2] [3]. For many passed years, a lot of works devoted to studying of nitropyrocatechin as analytical reagent for spectrophotometric determination of $\mathrm{Al}, \mathrm{Ga}, \mathrm{Ge}$ [4]. W [5], Mo [6], $\mathrm{Zr}$ [7] have been published. More recently, polyfunctional nitropyrocatechin with surface active com- 
pound are used widely and effectively in the analytical chemistry for spectrophotometric determination of metals [2] [3] [8].

Under the influence of surface-active compound (SAC), in metal-dryed organic reagent-SAC systems the great bathochromic shift and hyperchromic effect were observed within spectra of adsorption band of complexes [9].

The effect of SAC with nitropyrocatechin systems requires later studies and explanations. One of the disadvantages of these reagents is that the formed complexes are sparingly soluble. This drawback can be eliminated by using of modifying additives, especially SAC, which can also improve the chemical and analytical characteristics of these reagents.

In the presented work the reactions of $\mathrm{Ga}(\mathrm{III})$ with stillbazo (stillbene-4,4'bis[(1-azo)3,4-dihydroxybenzene]-2,2'-disulfonic acid) in the presence of cationic surface active compound (CSAC) - cetyl pyridinium chloride.

\section{Experimental Part}

\subsection{Apparatus and Reagents}

$1 \times 10^{-3} \mathrm{M}$ solution of $\mathrm{Ga}(\mathrm{III})$ prepared due to [10] technique, (a titer of solution has been found due to [11] method), $5 \cdot 10^{-3} \mathrm{M}$ aqueous solution of stillbazo, $1 \times$ $10^{-3} \mathrm{M}$ aqueous solution of cetyl pyridinium chloride were taken as initial reagents. $1 \mathrm{M}$ of $\mathrm{HCl}, 1 \mathrm{n}$ of $\mathrm{NaOH}$, ammonium acetate buffer solution ( $\mathrm{pH} 3.0$ 7.0) prepared with $2 \mathrm{M}$ of $\mathrm{CH}_{3} \mathrm{COOH}$ and $\mathrm{NH}_{3}$ were used for setting acetic medium; buffer solution with $\mathrm{pH} 1.0$ - 2.0 was prepared from fixanal solution of $\mathrm{HCl}$. $\mathrm{pH}$ value was controlled by $\mathrm{pH}$-meter of BENCHTOP METERS, the spectra were taken by UV-1800 and KFK-2.

\subsection{Experiment Procedure}

Suitable amount of solutions of stillbazo (stillbene-4,4'-bis[(1-azo)3,4-dihydroxybenzene]-2,2'-disulfonic acid) $(0.8 \mathrm{ml})$ and cetyl pyridinium chloride $(1 \mathrm{ml})$ have been added to the definite amount of solution of gallium(III) (1 ml) in flask of volume $25 \mathrm{ml}$. The optimal condition is achieved by using of buffer solution. Then the mixture has been diluted to the mark and shaked for 30 seconds. After all preparations colored solution has been transferred to the kuvette of $1 \mathrm{sm}$ and absorbance has been measured relative to the water. The analogical experiment has been carried out without gallium(III) and absorbance of reagent has been measured also relative to the water.

\section{Results and Their Discussion}

\subsection{Condition of Complexing and Spectral Characteristics}

The effect of $\mathrm{pH}$, concentration of stillbazo and CPC on the formation of complex compound of $\mathrm{Ga}$ (III) has been investigated.

When the reagents are mixed, the reddish-violet mixed ligand is formed. Complex formation taken place in $\mathrm{pH} 1$ - 6 .

The optimal $\mathrm{pH}$ for formation of mixed ligand complex is $\mathrm{pH}-2.1$, for un- 
mixed ligand complex is $\mathrm{pH}-5.6$.

$1.6 \times 10^{-4} \mathrm{M}$ concentration of reagent is required to completely connect $\mathrm{Ga}(\mathrm{III})$ ions in coordination compound. The nature of spectra remains stable with changing of $\mathrm{pH}$ of solution. The adsorption spectra of the reagent and its complex with $\mathrm{Ga}(\mathrm{III})$ were taken within various values of $\mathrm{pH}$ and within wide interval of the wave length.

It has been determined that the maximal adsorption of the reagent was observed at $\lambda=340 \mathrm{~nm}$, of the unmixed complex of $\mathrm{Ga}(\mathrm{III})$-stillbazo at $\lambda=400 \mathrm{~nm}$, of the mixed ligand complex of $\mathrm{Ga}(\mathrm{III})$-stillbazo-CPC at $\lambda=515 \mathrm{~nm}$ (Figure 1).

As seen from Figure 1, the existence of just one adsorption maximum in both cases demonstrates formation of the same complex. As it shows that there are not some adsorption maximum in the spectre, contrariwise there is only one adsorption maximum in both cases, respectively to homo and heteroligand complexes.

With increasing of concentration of stillbazo, the natures of the spectra do not change.

When include CPC in solution of unmixed ligand complex, the intensivity of lightadsorption increases, the complex formation shifts to more acidic zone, the contrast of reaction increases when micelle formation concentration (MFC) is (4 $\left.\times 10^{-5} \mathrm{M}\right)[12]$.
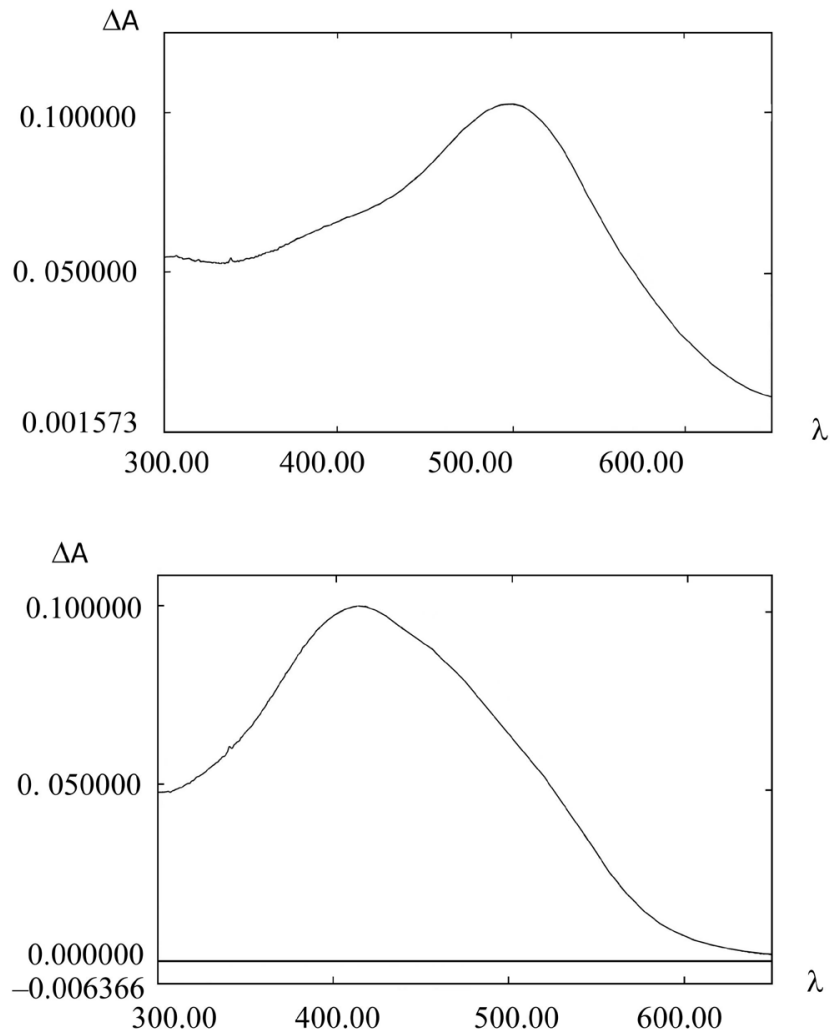

Figure 1. The adsorption spectra of the investigating compounds. 1) $\mathrm{Ga}(\mathrm{III})$-stillbazo; 2) $\mathrm{Ga}$ (III)-stillbazo-CPC. $\mathrm{C}_{\mathrm{Ga}(\mathrm{III})}=4 \times 10^{-5} \mathrm{M}, \mathrm{C}_{\mathrm{R}}=1.6 \times 10^{-4} \mathrm{M}, \mathrm{C}_{\mathrm{CP}}=4 \times 10^{-5} \mathrm{M}, \mathrm{UV}, 1800,1$ $=1 \mathrm{~cm}$. 
In adsorption spectra, a great hyperchromic effect and bathochromic shift to $115 \mathrm{~nm}$ were observed.

\subsection{Composition of the Complex}

Slightly soluble coordination compound is formed. Stability of complex remain for one day. The color of the complex is stable till $100^{\circ} \mathrm{C}$. With increasing of the temperature, the reddish-violet color of solution changes into yellow-orange color (the color of reagent).

SAC stabilizes the solution performing the functions of the protective colloids in which gelatin is commonly used [11].

The above-mentioned idea can be confirmed by the fact that, when the complex formation is actualized in aqueous-organic medium, the effect of increasing in the number of attached ligand is observed [12]. The dehydration process of metallic has been also observed in aqueous-organic medium, because of replacing water molecule of solvation shell with the molecules of corresponding solvent that prompt easier to displace their ligands.

The molar ratio of the components $\mathrm{Ga}(\mathrm{III})$-stilbazo-CPC $=1: 2: 4$ has been determined by various spectrophotometric methods [13] intersecting the curves of isomolar series.

The stability constant of the mixed ligand coordination compound $\beta=6.8 \cdot 10^{9}$ was gained by the method of intersecting the curves. The stability constant of unmixed ligand complex is $\beta=3.57$. the calculations indicated that the stability constant of the complex compound has increased extremely in presence of CPC.

\subsection{Determination of Gallium in Alunite}

The photometric method of the determination of $\mathrm{Ga}(\mathrm{III})$ in mixed ligand complex developed by us can be successfully applied to determine its microquantities in complex objects in the medium of accompanying elements.

Technique: In the first version, thoroughly diminished simple of $3 \mathrm{~g}$ of alunite was mixed with 6 times amount of anhydrous $\mathrm{Na}_{2} \mathrm{CO}_{3}$ and melted in a platinum crucible. The alloy was lixiviated with solution of hydrochloric acid (1:1). Solution was evaporated in a porcelain evaporating dish in the water bath until its drying, treated 2 - 3 times with concentrated solution of the hydrochloric acid and liberated from silicic acid, transferred to a volumetric flask of $200 \mathrm{~mL}$ volume, the volume was set to the mark with distilled water. We got $6 \mathrm{n}$ medium hydrochloric acid.

In the second version, $0.2 \mathrm{mg}$ of gallium was added into the alunite sample, elted as in first version. The results of investigation were indicated in Table 1.

Table 1. Determination of gallium in alunite $(\mathrm{P}=5, \rho=0.95)$ Found gallium, $\% 10^{-3}$.

\begin{tabular}{cccc}
\hline Analysis of an object & Reagent & The amount of gallium, \% & Sr \\
\hline Alunite & Stillbazo & $5.1 \times 10^{-3}$ & $4.9 \times 10^{-5}$ \\
& Rhodamine C & $5.0 \times 10^{-3}$ & $4.8 \times 10^{-5}$ \\
\hline
\end{tabular}


The molar coefficient of the mixed coordination compound is $\varepsilon_{c}=66834$, of unmixed ligand complex is $4.86 \times 10^{4}$ [14].

The calibrated graph is linear within $0.08-10.0 \mu \mathrm{g}$ concentration range of $\mathrm{Ga}$ (III) in $25 \mathrm{~mL}$ solution.

The study if the effect of extraneous ions on determination of $\mathrm{Ga}(\mathrm{III})$ as unmixed and mixed ligand complexes indicated that the selectivity of the reaction extremely increases in the presence of CPC. Under shown condition $\mathrm{Fe}(\mathrm{III})$, $\mathrm{Sb}$ (III), $\mathrm{F}^{-}$obstruct the determination of gallium.

\section{Conclusion}

The interaction between stillbazo and cetyl pyridinium chloride has been investigated. The optimal conditions of complex formation were found. The complex formation of $\mathrm{Ga}$ (III) with stillbazo was studied in the presence and absence of CPC. In the presence of CPC, the light adsorption of solution of gallium-stillbazo increases. The adsorption band of spectra exhibits a wide bathochromic shift and hyperchromic effect. The optimal density of solution of mixed ligand complex is maximum at the critical micelle concentration of CPC.

\section{Conflicts of Interest}

The authors declare no conflicts of interest regarding the publication of this paper.

\section{References}

[1] Amelin, V.G. and Ivanov, V.M. (2000) Test Analysis Method by Applying Paper-Immobilized Associates of Azo Derivatives of Pyrocatechol Trioxifluorones with Cetylpyridinium and Their Chelates with Metal Ions. Journal of Analytical Chemistry, 55, 411-418.

[2] Myasoyedova, A.S. (1977) Nitroderivatives of Pyrocatechin as Analytic Reagents for Tungsten.

[3] Myasoyedova, A.S., Ivanova, V.M. and Busev, A.I. (1975) Investigation of Analytical Chemistry. Vol. 30, 2398.

[4] Zagruzina, A.N., Ivanov, V.M. and Busev, A.I. (1978) Investigation of Analytical Chemistry. Vol. 33, 2395.

[5] Vilkova, O.M., Ivanov, V.M. and Busev, A.I. (1978) Investigation of Analytical Chemistry. Vol. 33, 716.

[6] Poledmok, J., Orzel, J., Galeczka, J. and Gzoik, P. (2017) A Highly Sensitive Spectrophotometric Method for Gallium Determination with Chrome Azurols in the Presence of Mixed Cationic-Anionic Surfactans and Its Application in Plant Analysis. Communications in Soil Science and Plant Analysis, 48, 8. https://doi.org/10.1080/00103624.2017.1311907

[7] Lomaco, Y.V. and Kuzmicheno, N.A. (2014) Application of Surface Active Compounds in Analysis of Medicinal Plants Containing Flavonoids. News of Pharmacy, No. 3, 65 .

[8] Filik, H., Tutem, E., Apak, R. and Erchah, E. (1998) Spectrophotometric Determination of Gallium (III) with Carminic Acid and Hexadecylpyridinium Chloride. Mikrochimica Acta, 129, 57-63. https://doi.org/10.1007/BF01246849 
[9] Chernova, R.K., Charlamova, L.N., Belousova, V.V. and Kulapina, Y.G. (1978) Chemistry and Chemical Technology for Students. 21, 46.

[10] Korestolev, P.P. (1964) The Preparing of Solutions for Chemico-Analytical Works. Science, 261.

[11] Nazarenko, V.A. and Antonovich, V.P. (1973) Trioxyfluorones. Science.

[12] Strelkova, K.V., Varigina, O.V., Chernova, R.K., Koblova, O.E. and Kostrichkiy, A.Yu. (2017) O vzaimodeystvii synteticheskogo pishevogo krasitelya E133 s kationami cetylpridinium, Izv. Sarat. Universiteta, 17, 376-381.

[13] Voropayeva, G.A., Kalinkiy, S.K. and Tarchina, V.D. (1970) Certificate of Authorship of SSSR. No. 265539. Bull. Invent. No. 10.

[14] Bulatov, M.I. and Kalinkiy, N.P. (1986) Practical Guide to Photometric Method. Chemistry, 432 . 